\title{
Women Empowerment: A Quantitative Exploration
}

\author{
Taseer Salahuddin* and Alia Ahmad
}

National College of Business Administration and Economics, Lahore, Pakistan

*Corresponding author: Dr Taseer Salahuddin, National College of Business Administration and Economics, Lahore, Pakistan, Tel: +92 (42) 3575-2716; Fax: +92 (42) 3575-2547; E-mail: salahuddin.taseer@gmail.com

Rec date: August 04, 2017; Acc date: September 09, 2017; Pub date: September 20, 2017

Copyright: (c) 2017 Salahuddin T, et al. This is an open-access article distributed under the terms of the Creative Commons Attribution License, which permits unrestricted use, distribution, and reproduction in any medium, provided the original author and source are credited.

\begin{abstract}
Empowerment is a value-laden cultural specific construct. Dimensions of women empowerment vary with variation of social, religious and cultural norms. Current article presents a quantitative analysis based on the culturally and socially specific dimensions of women empowerment derived via ethnographic exploration in Punjab, Pakistan. For the first time Alkire-Foster methodology of index building has been used to explore local composition and structure of women empowerment construct. Instead of using one-size-fit-all dimensions of women empowerment locally derived definitions would lead to targeted and effective policies. Therefore, measurement of level of empowerment among women and resultant policies for their empowerment is recommended based on this new method of measurement.
\end{abstract}

Keywords: Women empowerment; Gender and diversity; Methods; Punjab; Pakistan

\section{Introduction}

Empowerment is a value-laden construct and is derived from similar processes of participation, demanding and acquiring rights [1-4].

No common definition of this term exists [1-3,5-13] Multiple authors have agreed on the fact that empowerment is a combination of putting value to working in the community and understanding the processes and consequences of taking control over one's own life both in personal and professional sphere as well as community life $[6,14,15]$.

Empowerment represents an eclectic assortment of concepts and spread of outcomes by multitude of organizations and forums, such as the United Nations [16,17], the association for Women in Development [18], the declaration made at the Micro-Credit Summit $[19,20]$ and other organizations. Empowerment is one of the core discussion points for feminist researchers and activist [21] with varying degree of conceptualization and extent of discussion. Sen characterized empowerment as the process of removing several types of "unfreedoms" that limit individual choice and agency. Whereas Kabeer's [10] based on this characterization from Sen discusses links between individual agency with public action i.e., options, choice, control, and power [11,22] self-efficacy [10-13] as process $[10,11,13,23]$

Most elaborate definition of empowerment covering all aspects of above mentioned definitions are covered by United Nations definition of women empowerment where this construct is the sense of selfworth; choices; access to opportunities and resources; power to control their own lives, both within and outside the home; and ability to influence the world [24].

Multiple studies have tried to capture the construct of women empowerment with various dimensions [25-27]. All these studies have used either micro or macro level of aggregation for women empowerment and that influenced the type of dimensions used.
Uphoff and Albertyn have aggregated both micro [25,28] and macro levels [28] and developed holistic women empowerment measures. There has been enough evidence in international research that supports variation in the dimensions of women empowerment due to variation in cultures, norms, geographic location etc. $[10,27,29]$. There exists, a small body of academic literature which focuses on the need of a local definition of women empowerment especially before planning a women empowerment measure [30-33]. This study adds to the literature by quantitatively validating and exploring the results of cultural specific dimensions of women empowerment explored via ethnographic study [34].

\section{Literature Review}

\section{Women empowerment in Pakistan}

Situation of women empowerment in Pakistan measured by any standard or definition is in a dire need of improvement. International standards and reports show that issue of gender inequality and deprivation both are hindrances in the development of Pakistan (HDR 2007-08). Measures like GEM (Gender Empowerment Measure) and Gender Related Development Index (GRDI) rank Pakistan as low as 82nd among 93 registered countries of UN. These indicators are the counter measures of human development. Therefore, lower empowerment represents lower human development condition of a country. Similarly, according to Global Gender Gap report in 2016 Pakistan is second worst out of 144 countries. Furthermore, the disheartening part is that the situation has worsened over past year.

What will surprise the reader is the fact that from almost a decade women empowerment is one of the key discussion issues of government of Pakistan and other agencies within the country. Programs like Ordinance to free women prisoners, sensitization of media personnel, program to help young traders (opened by Prince Charles), approval of project Jafakush Aurat (Tharparkar), Community Mobilization Project completed in five districts, Women's political empowerment through capacity building and institutional strengthening, Establishment of five new women centres, IT training 
for elected women councillors in local government, passage of women Protection act, approval for $10 \%$ quota for women across the board, IT training of elected lady representatives, Successful completion of Media Campaign, CEDAW debriefing session on women empowerment and National policy for the development and empowerment of Women in 2002 etc. have been initiated for the purpose of improving the situation of women empowerment and gender equality. A question that comes to mind is that why did all these efforts fail to impact the situation of women?

There are efforts going on by the researchers and institutions to gauge the true situation of women in Pakistan and to point out the causes of the low development and empowerment of Pakistani women. One such study was conducted by Sustainable Development Policy Institute SDPI [35]. Their main finding shows that in education, health, agriculture and overall economy gender inequality is high with little empowerment of women. In education sector women enrolment rate is low with high dropout rate. Gender inequality in education can be seen in rural areas.

In health sector, for both genders health facilities are over-burdened, with high dependencies on donor agencies and poor reforms. Women suffer from low mobility which does not let them take advantage of economic opportunities away from home. They suffer from heavy share of agricultural labour. Decision making power of women is limited both at home and outside. In short, gender discrimination prevails in all sectors. This situation if evident from a peek into governmental and non-governmental statistics on gender classification in different sectors.

The awareness of the fact that Pakistan is one of the most poorly performing countries in gender domain around the globe demands immediate attention to investigation of the true women empowerment and exploration of local determinants of women empowerment in the country.

Using locally explored dimensions a survey questionnaire was distributed to 2000 females across Punjab, with response of 1799. This $89.95 \%$ of response rate was very encouraging. Based on the quantitative data a range of indices were built using a variant of Alkire Foster Methodology [34].

Empowerment construct was generated by scoring and dividing into spectrums. It was divided into three bands, not empowered, partially empowered and empowered respectively. Band widths were decided on the basis on scoring range of Likert responses of agreement and disagreement range. Dimension and indicator selection was done based on Exploratory Factor Analysis.

This measure originally designed to measure poverty consists of two steps (i) identification method which uses traditional intersection and union approaches and is two stepped itself (a) identification of cut-off at dimension level which decides if a person is empowered in that particular dimension and (b) a second overall cut-off which decides the number of dimensions one has to be deprived off to be considered as disempowered (ii) an adjusted head count ratio M0 that signifies a range of desirable properties. Aggregation is done in this measure by an extension of FGT measure adjusted for multidimensionality.

\section{Women empowerment demographics}

It was expected that due to better living standards, more education, better health facilities and other factors women empowerment would be more in urban areas. Contrarily it was seen that women in rural areas were slightly more empowered as compared to urban women. There were $47.4 \%$ 'not empowered' women in urban area while rest of $52.6 \%$ women were either partially empowered or empowered. While in rural areas $59.5 \%$ of women were partially or fully empowered and only $40.5 \%$ were not empowered.

Does this 'observed' empowerment difference in our sample indicate population association between area and empowerment? To answer this question Chi-Square test was applied. Results showed evidence of such association with Chi-Square value of 11.1 at a significance of $\mathrm{P}=0.004$. Likelihood ratio test also supported this conclusion.

Age in cross tabulation with empowerment illustrated cyclical stages of empowerment. Contrary to discussion in literature age does not show a linear or simple relation with empowerment. It is seen that females in early age especially when still with their own parents are slightly more empowered than during early years of their married life. As the age advances and their children grow up plus the initial pressures of married life decrease their empowerment increases while it decreases again if a female's married life is disrupted.

Age showed a weak cyclical relationship with empowerment in this sample. To check association in population Chi-Square test was applied. Results showed weak evidence of such association with ChiSquare value of 9.941 at a significance of $\mathrm{P}=0.127$. Likelihood ratio test also supported this conclusion.

Education empowerment cross tabulation showed a significant impact of education level on empowerment, although this relationship is not exactly linear. This is evident from the fact that totally $7.1 \%$ uneducated females were totally empowered and even 2 of the postgraduate females depicted not empowered status.

Education showed a significant relationship with empowerment in this sample. To check association in population Chi-Square test was applied. Results showed weak evidence of such association with ChiSquare value of 32.606 at a significance of $\mathrm{P}=0.001$. Likelihood ratio test also supported this conclusion. Work status and empowerment cross tabulation depicted a weak relationship between the two variables. Chi-square test illustrated a weak relationship with Chisquare value of 10.73 at $\mathrm{P}=0.097$. These results are also supported by the likelihood ratio.

A significant relationship was seen between marital status and empowerment level. It is apparent that for a female in Punjab empowerment level is slightly higher before and during marriage. However, it is hard for divorced, separated or widowed females to generally lead an empowered life. This is also evident from the chisquare results which show a significant association between marital status and empowerment level with Chi-Square value at 19.395 at $\mathrm{P}=0.036$.

Contrary to the beliefs of women in qualitative analysis number of sons a female bore had no significance what so ever in determining the level of her empowerment. This is evident from both the crosstabulation between the two variables and Chi-square value. In cross tabs, it is seen that $22.2 \%$ of those who had no sons at all were totally empowered the same percentage as those who had 5-6 sons. ChiSquare results also defy any association between the two variables at population level. This is evident from Chi-Square value of 5.234 at $\mathrm{P}=0.732$. Income class demonstrated a significant impact on women empowerment in Punjab. These results were not surprising at all. They show that as the income class improved empowerment that a female enjoyed inclined. Percentage of females who were not empowered 


\section{$10.4172 / 2167-0358.1000218$}

This conclusion was also
test with value of 66.698 at increased as the income class decreased. This conclusion was also
supported by the results of Chi-Square test with value of 66.698 at $\mathrm{P}=0.00$.

\section{Women empowerment index}

To build women empowerment index first exploratory factor analysis was done to determine the dimensions and indicators [36]. It was used to ascertain the validity of items included in the questionnaire. First and foremost, we need to check if our correlation matrix. This table shows Pearson correlation coefficients in the top part and significance values in the bottom. We need to see those variables having significant values greater than 0.05 because these indicate possibility of multi collinearity between the variables [36]. Initially when the factor analysis was run it resulted in not positive determinant matrix. Looking carefully on the correlation matrix two variables namely, 'family occupation perception' and 'income class perception' had to be removed as they were highly correlated with social prestige perception' this was causing multi collinearity in data.

After their removal, current results were received with significant values below 0.05 . For further surety, KMO measure of sample adequacy and Bartlett's Test for sphericity were applied. Value of KMO was 0.962 which was high enough to show that sample size was adequate for analysis and Bartlett's test of Sphericity showed high significance for the application of EFA by supporting the possibility of finding some useful relationships during the analysis [36]. This shows that multi collinearity is not a problem in this data set. All the questions correlate well enough and none of the correlation coefficients are very large, as a result we do not need to consider eliminating any other question.

Next output in SPSS of EFA is the Total Variance Explained table. This table shows that before extraction 83 linear components in data, but after extraction 15 components were reported. Each value is an eigenvalue showing the $\%$ age of variance explained by that component. This is evident that first five components explain large variance while rest explains smaller variance. However, EFA extracted all components explaining greater than 1 . Here researcher has used Kaiser Criterion for extracting components and hence has kept all components with values greater than 1 .

According to Kaiser Criterion if communalities $>0.7$, sample $>250$ then keep all components having values greater than 1 [36]. If communalities are observed, values are greater than 0.40. Apart from two variables excluded at the beginning of the analysis, inclusion of the rest of the variables was supported. This is also supported by the scree plot which shows fifteen factors with five explaining major variance and rest small part before the slope becomes zero. Arrow sign depicts the exact position.

Next important output of SPSS EFA is the rotated component Matrix which shows the loading of variables of each component. As our data was unrelated therefore, we have applied Varimax rotation. At this stage researcher after looking carefully at the questions loaded at the same component came up with the dimensions based on the related questions. After the rotated component matrix, a table for before EFA model and after EFA dimensions and indicators is shown. After EFA following dimensions were created for empowerment (Figure 1).

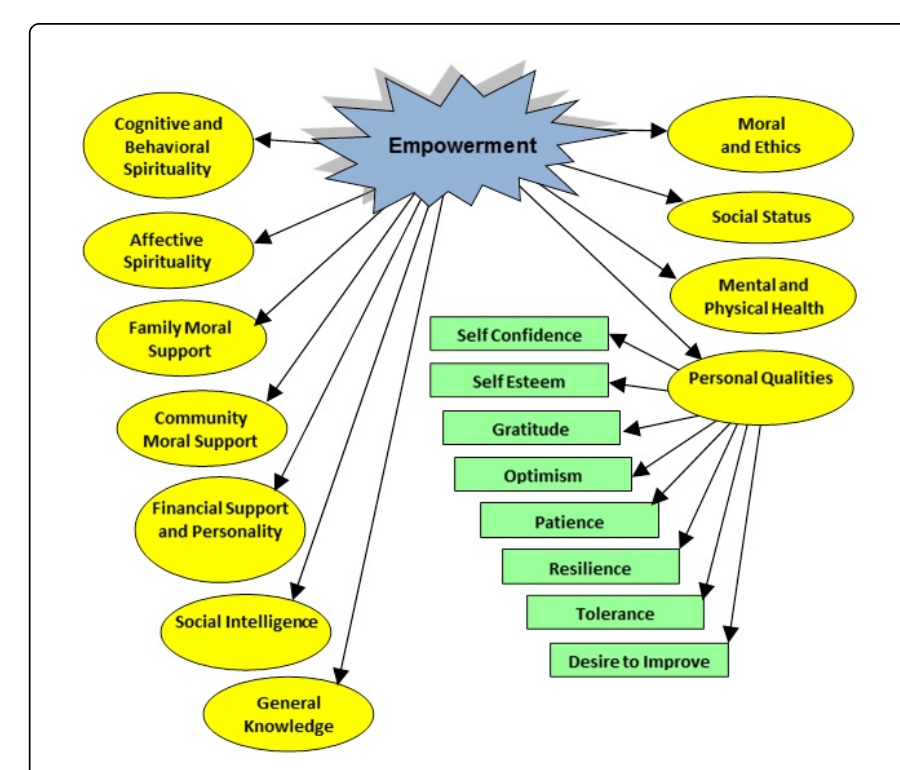

Figure 1: Model generated for women empowerment.

Using these dimensions and indicators generated by EFA women empowerment index was generated using a variant of MDDS in 2015 and Alkire Foster methodology. For that again certain steps were followed:

Step 1: In first step unit of analysis is selected, which in our case was the household of the female participants.

Step 2: In second step dimensions for analysis were selected, these dimensions were based on Salahuddin and Zaman [34]. Education, type of housing, electricity, assets, air quality, water and sanitation, income class were the dimensions added for analysis.

Step 3: Third step consisted of choosing indicators. This was also based on Salahuddin and Zaman [34].

Step 4: This step was the application of first cut-off of deprivation lines. Here in each indicator value 1 was assigned for all those options defined as deprived and value 0 was assigned for not deprived options.

Step 5: This step consisted of summation of total deprivation scores of each female. This variable was named as MDDS scores.

Step 6: In step 6 a new variable MDDS was coded when total scores were redefined into ranges of spectrum of deprivations. Anyone having scores 1-2 was recoded as 1 (not deprived),

3-4 as 2 (slightly deprived), 5-6 as 3 (moderately deprived), 7 as 4 (highly deprived) and 8 as 5 (absolutely deprived).

Step 7: Seventh step consisted of calculation of average deprivation share 'A' for each band of spectrum. To calculate A for each band/slab average deprivation per score included in the band is to be summed and then over all deprivation share is calculated by taking the average. For example, scores 1 and 2 are added to first slab representing not deprived band. For it $A 1=(1 / 8+2 / 8) / 2=0.1875$. This represents that individuals falling in not deprived band have $18.75 \%$ of deprivations in their lives. This percentage is small enough to be labelled as not deprived.

Step 8: In step 8 headcount $\mathrm{H}$ was calculated by frequency table generation for each band of spectrum using frequency table given 
below. For not deprived band $\mathrm{H} 1=465 / 1799=0.258$. It means $25.8 \%$ females fall into the band of not deprived (Table 1).

\begin{tabular}{|c|c|c|}
\hline Variables & Score & $\%$ \\
\hline Not empowered & (Less than $25 \%$ of score $)$ & $46.40 \%$ \\
\hline Partially empowered & $(25 \%$ to $<50 \%$ of score $)$ & $30.50 \%$ \\
\hline Empowered & $(>50 \%$ of score $)$ & $23.10 \%$ \\
\hline
\end{tabular}

Table 1: Empowerment spectrum

Step 9: Multidimensional deprivation spectrum is built using five indices, one for each band. Each index is the product of headcount and average deprivation share of each band. For example, for not deprived band

$$
\mathrm{M} 1=\mathrm{A} 1 \times \mathrm{H} 1=0.1875 \times 0.25 .8=0.048 .
$$

This index is the adjusted head count ratio derived in Alkire Foster methodology. It not only represents the incidence of deprivation in not deprived band but also shows the depth of deprivation. Larger $M$ represents both larger headcount and larger average deprivation share.

Rest of the indices of deprivation is summarized in the following table. Which show average share of deprivations per band and percentage of deprived individuals per band, along with index value.

Those females having $50 \%$ of average empowerment share (partially empowered) were $30.5 \%$ of the total sample. $23.1 \%$ of the sample were empowered having $58.4 \%$ average share of empowerments. This is again not a very encouraging scenario as almost half of the females reported to have less than $50 \%$ of average empowerment. However, it was encouraging to note that around $25 \%$ of the total sample enjoyed more than $50 \%$ empowerment.

\section{Discussion}

Sensoy and Marshall [37] claim that West considers South Asian Women as the victims of their culture and they are pictured as the oppressed, submissive creatures with no will of their own with a need to be rescued via western feminist approach. Current research wanted to explore if that was right. One way of establishing this claim as truth would be investigating if western definition of women empowerment also prevails in the heart and minds of Pakistani women? If their definition was the same, then this claim could be considered true. Otherwise, this research could lead to the cultural and social differences in the definitions of women empowerment between West and here, rendering empowerment studies and measures based on western definitions useless for local benefit. With narrative inquiries and in depth semi-structured interviews local dimensions and indicators of women empowerment were explored. These were then validated via EFA and the utilized in quantitative analysis for establishing of facts.

Dimensions and indicators which are frequently used by west to measure women empowerment included education, income control, decision making power, political and economic representation in society etc [27]. However, the dimensions which resulted from local qualitative exploration were not only drastically different they were also different in approach or paradigm of existence. Dimensions from the qualitative analysis were all micro level or individual connected dimensions. They included cognitive and behavioural spirituality, affective spirituality, personal qualities, family and community moral support, social status and financial support, desire to improve and general knowledge. Strongest dimension that emerged from the analysis was personal qualities including, self-confidence, self-esteem, resilience, gratitude, patience, optimism and tolerance of an individual.

\section{Conclusion}

A proof of the difference between IWE western and LWE local definition of empowerment was the level of higher empowerment in rural areas as compared to urban areas. It was expected that due to better income opportunities, better educational prospects, improved standard of living and greater general awareness, urban women would be more empowered than their rural counterparts. On the contrary, rural women were more empowered due to well-connected family and community support networks, more spiritual trends and increased awareness due to mobile internet and smart phone technology.

Last but not the least, variation within the cultures of one province (Punjab), made it very clear that a flexible measure of empowerment which focuses on culturally significant dimensions is used for catering all this variation. This also points out that borrowed definitions cannot be as useful as locally generated ones for measurement of cultural specific construct.

It is apparent that due to major conceptual as well as measurement differences in the two definitions conventional definitions of empowerment cannot be used to study empowerment in Pakistan to devise measures and policies for improving empowerment of women.

One-size-fit-all definitions of such complex constructs as empowerment would lead to misrepresentation of the idea and would lead to misdirected policies. This in turn would lead to misallocation of resources. Using a wrong definition and measurement criteria for a construct is as if one is trying to measure temperature via barometer. If a doctor does not know the true symptoms of a disease, diagnosis will be wrong and therefore right prescription and cure cannot be expected.

Before measurement appropriate definition of a concept is very necessary. If we are designing our women empowerment initiatives and policies based on borrowed definitions, policies will keep on failing as they have up till now. Having separate ministry of Women development or making women empowerment as a target for development plans will not help unless and until measurement of women empowerment is done based on local perceptions of empowerment, considering our cultural ties, moral and religious values and social demands. One major difference between policy targets of both definitions is that conventional definition considers empowerment as a secular paradigm and only focuses on the policies that target women alone. In our culture women is a part of interwoven and intricate social networks that cannot be empowered without overall general empowerment of society.

\section{References}

1. Kindervatter S (1978) Nonformal education towards empowering. Chapter VII in nonformal education as an empowering process. Amherst, MA, Center for International Education, USA.

2. Gutierrez LM (1988) Coping with stressful life events: An empowerment perspective. Working Paper, School of Social Work, University of Michigan, Ann Arbor, MI, USA.

3. Zimmerman MA, Rappaport J (1988) Citizen participation, perceived control, and psychological empowerment. Am J Community Psychol 16: $725-750$. 
4. Israel BA, Checkoway B, Schulz A, Zimmerman M (1994) Health education and community empowerment: Conceptualizing and measuring perceptions of individual, organizational, and community control. Health Edu Behav 21: 149-170.

5. Braithwaite RL, Lythcott N (1989) Community empowerment as a strategy for health promotion for black and other minority populations. JAMA 261: 282-283.

6. Rappaport J (1981) In praise of paradox: A social policy of empowerment over prevention. Am J Community Psychol 9: 1-25.

7. Wallerstein N (1988) Empowerment education: Freire's theories applied to health a case study of alcohol prevention for Indian and Hispanic youth (Vol. 2). University of California, Berkeley, USA.

8. Wallerstein N (1992) Powerlessness, empowerment, and health: Implications for health promotion programs. Am J Health Promotion 6: 197-205.

9. Freire P (1970) Pedagogy of the oppressed. The Seabury Press, New York, NY, USA.

10. Kabeer N (2001) Reflections on the measurement of women's empowerment. In discussing women's empowerment-theory and practice. Sida Studies No. 3. NovumGrafiska AB: Stockholm, Sweden.

11. Rowlands J (1995) Empowerment examined. Develop in Practice 5: 101-107.

12. Nussbaum MC (2000) Women and human development: The capabilities approach, Cambridge University Press, Cambridge, UK.

13. Chen M (1992) Conceptual model for women's empowerment. Unpublished.

14. Perkins DD, Zimmerman MA (1995) Empowerment theory, research and application. An introduction to a special issue. Am J Community Psychol 23: 569-579.

15. Zimmerman MA, Warschausky S (1991) Empowerment theory for rehabilitation research: Conceptual and methodological issues. Rehab Psychol 43: 3-16.

16. UN Division for the Advancement of Women (UNDAW) Department of Economic and Social Affairs (2001) Empowerment of women throughout the life cycle as a transformative strategy for poverty eradication. Report of the expert group meeting, 26-29 November. New Delhi, India.

17. UNICEF (1999) Human rights for children and women: How UNICEF helps make them a reality. United Nations Children's Fund, New York, USA.

18. Everett J (1991) The global empowerment of women. Summary of the annual conference of the association for women in development, 1989, Washington DC, USA.

19. Results (1997) The Micro-Credit Summit. Declaration and Plan of Action, Wahington D.C, USA.

20. DFID Department for International Development (2000) Poverty elimination and the empowerment of women: Strategies for achieving the international development targets. London, UK.
21. Jahan R (1995) The elusive Agenda: Mainstreaming women in development. Zed Books Ltd, Atlantic Highlands, NJ, USA.

22. Batliwala S (1994) The meaning of women's empowerment: New concepts from action. In: Sen G, Germain A and Chen LC (eds). Population policies reconsidered: Health, empowerment and rights. Cambridge: Harvard University Press, UK.

23. Oxaal Z, Sally B (1997) Gender and empowerment: Definitions, approaches and implications for policy. Bridge Report No. 40. Sussex: Institute of Development Studies.

24. UN (2015) Beijing Women 2000: Gender equality, development and peace for the 21st century twenty-third special session of the general assembly.

25. Malhotra A, Schuler SR, Boender C (2002) Measuring women's empowerment as a variable in international development. Background paper prepared for the World Bank Workshop on poverty and gender: New Perspectives.

26. Jejeebhoy SJ, Zeba AS (2001) Women's autonomy in India and Pakistan: The influence of religion and region. Population Develop Review 27: 687-712.

27. Kabeer N (2010) Gender Equality and Women's Empowerment: A Critical Analysis of the Third Millennium Development Goal. Gender and Development 13: 13-24.

28. Chaudhary AR, Chani MI, Pervaiz Z (2012) An analysis of different approaches to women empowerment: A case study of Pakistan. World Appl Sci J 16: 971-980.

29. Kabeer N (2003) Mainstreaming gender in deprivation eradication and the Millennium Development Goals. London: Commonwealth Secretariat/IDRC Publication, UK.

30. Kimani N, Orchardson-Mazrui E (2013) Gender inequality and women's rights in the great lakes: Can culture contribute to women's empowerment. UNICEF policy document, NY, USA.

31. Rui H (2013) Chinese people's perceptions of gender inequality, Lund University, Sweden.

32. Hawa NM (2015) Kenya and Somalia: Fragile constitutional gains for women and the threat of patriarchy. Afr Sec Review 24: 458-474.

33. Ndimande-Hlongwa N, Rushubirwa R (2014) Gender inequality and language reflections in African indigenous languages: Comparative cases from IsiZulu and Kiswahili.

34. Salahuddin T, Zaman A (2012) Multidimensional poverty measurement in Pakistan: Time series trends. Pak Develop Review 51: Part II.

35. https://www.sdpi.org/publications/report_files/2007-08.pdf

36. Field AP (2005) Discovering statistics using SPSS (2nd edn). London: Sage Publishers, UK.

37. Sensoy O, Marshall E (2010) Missionary girl power: Saving the "Third World' one girl at a time. Gender Educat 22: 295-311. 